\title{
An integrative review of the role of remittances in international nurse migration
}

\author{
This article was published in the following Dove Press journal: \\ Nursing: Research and Reviews \\ 30 December 2014 \\ Number of times this article has been viewed
}

\author{
Allison Squires' \\ Angela Amico ${ }^{2}$ \\ 'College of Nursing, ${ }^{2}$ Global Institute \\ of Public Health, New York University, \\ New York, NY, USA
}

\begin{abstract}
This review seeks to understand the role of remittances in international nurse migration within the context of three theories of international migration: equilibrium approaches, social networks, and globalization. To analyze the phenomenon, an integrative review of the literature was conducted. Search terms sought articles discussing, either directly or indirectly, remittances and international nurse migration. The initial search returned 369 articles, and further screening decreased the total to 65 . Full text screening reduced the final number for the analysis to 48 . A directed content analysis structured the analytic approach by examining how authors discussed remittances in the content and context of the paper. The final analysis showed the majority of papers were policy analyses (five); opinion papers, reviews, or editorials that indirectly discussed remittances (27); or were qualitative and quantitative studies (16), either with primary data collection (14) or secondary data analyses (two). Overall, a nurse's individual motivation for sending remittances home stemmed from familial factors but was never a primary driver of migration. Domestic labor market factors were more likely to drive nurses to migrate. The nurse's country of origin also was a factor in the remittance dynamic. The identity of the author of the paper played a role in how they discussed remittances in the context of international nurse migration. The three theories of migration helped explain various aspects of the role of remittances in international nursing migration. While the phenomenon has changed since the 2008 global economic crisis and the passing of the World Health Organization's Global Code of Practice on the International Recruitment of Health Personnel in 2010, future research around the role of remittances needs to consider the confluence of gender, social, political, labor market, and economic dynamics, and not just view the phenomenon from an individual lens.
\end{abstract}

Keywords: nursing, health care worker, remittance

\section{Introduction}

In 2010, the World Health Organization passed the Global Code of Practice on the International Recruitment of Health Personnel. ${ }^{1}$ The code was passed in response to a decade of growth in international health worker migration fueled by forces of globalization, the human immunodeficiency virus/acquired immune deficiency syndrome epidemic in sub-Saharan Africa, and other locally specific factors that drove record numbers of health care providers abroad for work and left many health care systems with critical health worker shortages. ${ }^{1,2}$ While the passing of the code coupled with the 2008 global economic crisis has changed the dynamics behind migration and health labor markets since then, remittances from these emigrated workers still play a significant role in the economies of many countries.
Correspondence: Allison Squires

College of Nursing, New York

University, 726 Broadway, I0th Floor,

New York, NY 10003, USA

Tel + I 2129927074

Email aps6@nyu.edu 
Remittances are money transfers sent back to the home country by the worker abroad. ${ }^{3,4}$ For some countries, remittances comprise as much as $10 \%$ of the gross national product. ${ }^{2}$ In some cases, the economic significance of remittances to a country's economy provides governments with multiple incentives to encourage emigration so they can capitalize on the economic gains from such returns. ${ }^{5-7}$

In the case of nurses migrating internationally for work opportunities, remittances are a known and expected part of their migration experiences. ${ }^{8}$ A clear conceptual understanding of the role of remittances in international nurse migration (INM) and the extent to which they drive the phenomenon, however, has not yet been established. Thus, the purpose of this review is to conduct an integrative review using directed content analysis techniques of literature that directly or indirectly addresses the issue of remittances in INM in order to gain a better conceptual understanding of its role in the migration experiences of nurses.

\section{Background}

International migration occurs when an individual chooses to leave his or her home country to live and work in another one. Factors driving migration include war/conflict, ethnic, or racial genocide; lack of employment opportunities and other economic issues in a home country; interest in gaining professional experience abroad; and the personal desire to see new places or have new experiences. Migration is also a policy often used for national economic stabilization in regions like Latin America. ${ }^{9} 10$

INM is a multibillion dollar phenomenon that affects countries around the world, and one that health care organizations use to address significant staff vacancies. ${ }^{6,11-24}$ Most nurses migrate internationally from low- and middle-income countries to work in high-income ones. They often remain permanently in the high-income country and never return to their places of birth, but do send millions of dollars in remittances to their home country. ${ }^{19}$ The consequence to the developing world includes poorer health outcomes due to a lack of professional personnel to deliver health care services and poorly functioning health systems, to name a few. ${ }^{2}$

As a discipline, migration researchers cite three main theoretical schools of thought surrounding international migration: equilibrium approaches shaped by neoclassical economics; household and network approaches that prove the best for capturing gender dynamics involved in international migration; and globalization theories that assume a certain amount of inevitability about international migration as a phenomenon. ${ }^{25}$ With each theory, the role of remittances will be distinct.
First, equilibrium approaches shape the majority of studies about INM, focusing on push-pull factors. The 2003 breakthrough study by Buchan et al, ${ }^{6}$ under the equilibrium migration model, highlights "push factors" - domestic conditions influencing nurses' decisions to migrate. For nurses, push factors include several key components, mostly centered on low salaries and poor working conditions. Personal safety in the workplace and the home country of the nurses was also a driving factor. "Pull factors" include characteristics of the country attracting the nurse and the opportunity for aid work or to travel. The significantly higher salaries of nurses in high income countries also attract many nurses abroad. Thus, remittances represent a combination of both push and pull factors, resulting from new opportunities with the possibility of providing economic stabilization abroad, and in some cases, alleviating poverty for their families at home. Trade advocates, who are usually major supporters of migration for work to increase remittances for the purposes of economic development, draw from equilibrium approaches in their regulatory recommendations around trade in health services. Free market advocates push for minimal regulation of trade in health to maximize the potential of remittances, ${ }^{5,26,27}$ while others show how the policies exacerbate inequality. ${ }^{28-30}$

Equilibrium approaches, however, fail to factor in gender and social conditions that often drive INM and to whom remittances are sent. Household and network approaches provide interesting alternative explanations sensitive to the gender dynamics involved with INM..$^{31,32}$ Robinson et al ${ }^{13}$ suggest that age, family factors, and the presence of children affect migration decisions, acting as retention factors for some locations while driving migration in others, largely because of the potential support from remittances. Yet, that school of thought minimizes the labor market effects found in both equilibrium and globalization theories of international migration.

Finally, the globalization approach makes a core assumption that, once the market opens up through trade and other international regulations, people will inevitably migrate. Remittances serve as a primary, individual incentive in this theory. The globalization approach is the only one that incorporates state immigration policies as a potential driving factor since they have a long history of influencing INM trends. The state as a variable in the INM equation, however, is often understudied. ${ }^{25,31,34-36}$ Therefore, the state could set policies to capitalize on the potential of remittances as an economic driver because globalization has greatly facilitated the possibility of remittances. The Philippines, for example, has these types of policies. ${ }^{5}$ 
All three theories inform our thinking about how we analyze the role of remittances in INM. We seek to understand the dynamics of remittances within the phenomenon based on the precepts of each of these theories.

\section{Methods}

We conducted an integrative review of the INM literature to specifically focus on the role of remittances in this international dynamic and used a directed content analysis approach to analyze the documents. Integrative reviews seek to synthesize evidence from various sources to capture multiple dimensions of a phenomenon. ${ }^{37}$ Studies are selected for their content relevance to the question, and research rigor is not evaluated. The larger volume of studies and documents analyzed in an integrative review is thought to create a more comprehensive picture of a phenomenon. ${ }^{37}$ Directed content analysis focuses specifically on a set of author-identified terms identified as important to answering the research question but still allows for themes and categories to iteratively emerge from the analysis. ${ }^{38}$

To select articles from both health and social science disciplines known to study INM, we conducted a literature search using Cumulative Index to Nursing and Allied Health Literature, Ovid Medline (medicine), and Web of Science (social sciences) databases with the terms "Nurs* AND migration", "foreign nurses", "internationally educated nurses", "Nurs* AND incentive AND migration", and "Nurs* AND remittances". Limited to publications after 1994, the search was then narrowed to include only the terms "Nurs* AND incentive AND migration" and "Nurs* AND remittances", which returned 264 and 167 articles, respectively. Duplicate articles were removed and the remaining titles (369) were screened for eligibility. Articles had to address international or foreign nurses and remittances or financial incentives in some way. Grey literature was excluded for feasibility reasons. We also operated under the assumption that the selected articles would largely capture nurses migrating by choice for work and not due to political instability or war. Choice in migration is an important factor in remittances dynamics. The flow diagram in Figure 1 illustrates our search and selection process.

Ultimately, 65 titles were identified, and their abstracts and full texts were reviewed. Seventeen publications were excluded because they did not address remittances or incentives of migration, or were not informative sources (eg, book review, call for abstracts, etc). A total of 48 articles were included and chosen for how they addressed remittances in the body of the work.

We adopted a directed content analysis approach to analyze the final 48 articles. We specifically looked for how authors discussed remittances or financial incentives in the article and the context of their discussion. Themes and categories not in our initial codes were allowed to emerge iteratively during the analytic process. Then, based on criteria described by Miller and Alvarado for managing documents serving as data, ${ }^{39}$ we examined both the content of the articles around remittances and the context in which the author discussed them. The combined approach enabled us to synthesize our findings into a coherent picture of the role of remittances in INM.

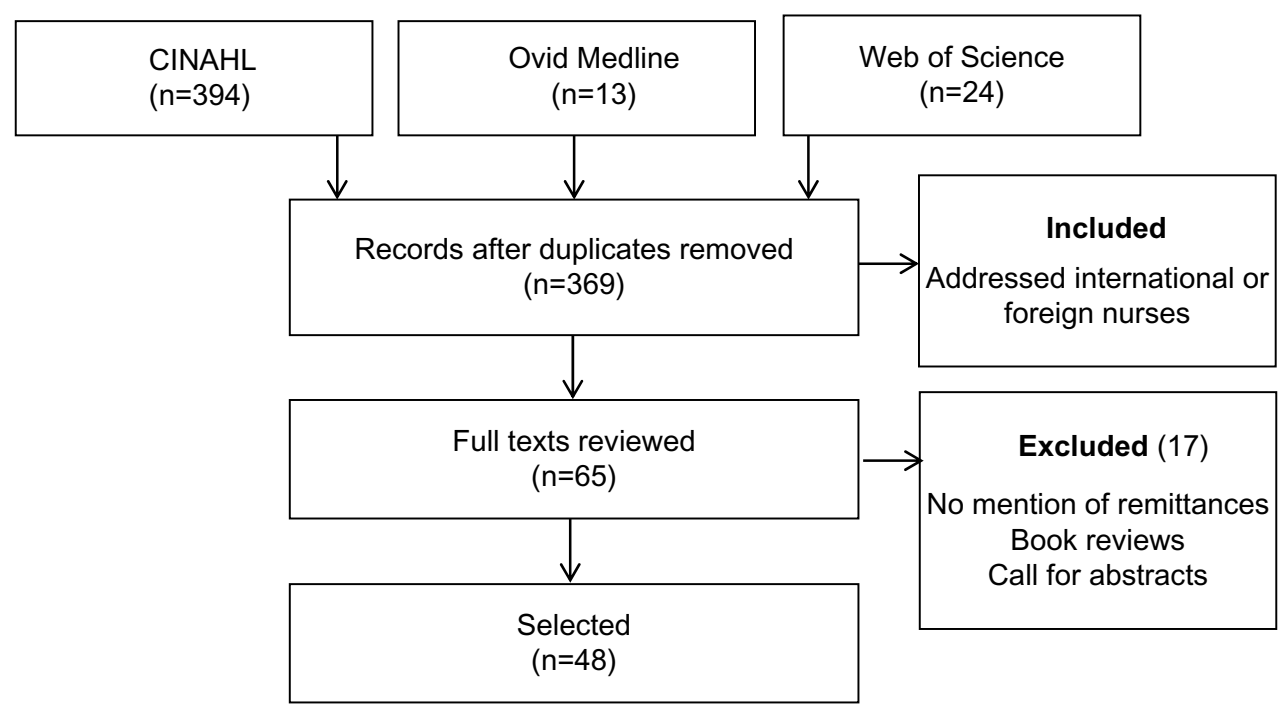

Figure I Search strategy for the literature review.

Abbreviation: CINAHL, Cumulative Index to Nursing and Allied Health Literature. 


\section{Results}

An important trend observed during our search and the resulting literature is that overall, discussions of or research about INM, including remittances, has dropped significantly since 2011. This likely reflects the decrease in nurse migration resulting from the combination of the 2008 global economic crisis and national policy changes freezing international health worker recruitment that were enacted after the 2010 passing of the global code for ethical international recruitment of health care workers. The demand for internationally educated nurses dropped as the combination of one or more of the following happened in receiving countries: 1) slowed hiring in response to the economic crisis, 2) domestic labor market production of nurses approached equilibrium, and 3 ) nursing schools increased enrollments and graduates. ${ }^{40}$ Therefore, most of the articles included in this analysis come from the peak international migration period between 2000 and 2009. Authors in these interdisciplinary articles do consistently note that it is nearly impossible to obtain reliable data on the amount of remittances sent to home countries by health workers alone. If remittance numbers are reported, the state reports them in aggregate form and rarely by discipline.

Of the articles selected for the analysis, 16 were qualitative, quantitative, or mixed methods; five were policy analyses; and 27 were categorized as level VII evidence (opinions, editorials, etc). Findings represent the perspectives of more than 7,000 nurses from 17 sending countries, and six receiving countries. Table 1 outlines the articles included in this integrative review.

Notably, only two articles directly addressed the topic of remittances among migrating nursing personnel. All other articles addressed the topic indirectly or it emerged as a factor in the migration issues discussed in the paper.

An interesting finding was how author identity affected discussions of remittances in the papers. Nurses in high-level policy positions or nonnurses were more likely to attribute individual motivation to migrate as affecting remittances without examining the larger picture of the contextual factors driving nurse migration or asking nurses themselves. Researchers studying the phenomenon, using quantitative or qualitative techniques, were more likely to be nurses than nonnurses. Evidence directly from nurses expanded the picture of the role of remittances beyond assumptions behind individual motivators.

Overall, however, we concluded from our analysis that the incentive provided by remittances represented, as a crude estimate, only about $25 \%$ of the motivating factors driving INM. We draw this conclusion from several trends in the analysis.

First, when remittances or other financial incentives are mentioned by nurses in qualitative studies, they are not extensively discussed and usually mentioned in what appears to be passing fashion in the manuscript. ${ }^{41-49}$ This may be due to how the authors chose to present the information in the paper or how nurses were asked about remittances in the studies (directly or as something that might naturally emerge in the interview).

Quantitative studies also showed that remittances are one factor of many involved in the migration dynamic. ${ }^{44,50-56}$ The domestic context of career advancement opportunities, working conditions, system management quality, and other factors prevailed as stronger factors influencing migration. Results from these studies, however, fit better into a domestic health labor market conceptual framework, like that described by McPake et al. ${ }^{57}$ Within that lens, remittances from working abroad do not factor into domestic health labor market dynamics for nurses.

In contrast to formal research studies, editorials and opinion papers would consistently cite remittances as major individual factors involved with INM. Remittances were discussed with mixed perspectives, ranging from the socioeconomic benefits conferred on nurses' families to the "perceived" negative role as a driver of state policies encouraging migration to improve national gross domestic product statistics, along with links between remittances, exploitation of nurses, and recruitment companies' fees. ${ }^{58-80}$

Policy analyses covered very distinct issues related to remittances and migration. Chanda studied remittances through a trade lens and viewed them as a critical component that facilitates global trade, with health workers in general contributing significantly to the phenomenon. ${ }^{62}$ A later publication with other colleagues from the health and trade disciplines on the same topic updated the arguments made in the 2002 paper yet still came out in support of remittances. ${ }^{81}$ These papers fit best into the equilibrium approaches theoretical framework. Kingma, ${ }^{67,68}$ a nurse herself, has led the policy analyses for INM within the field of nursing, and her results also come from equilibrium approaches. Her work, which specifically mentions remittances, takes a balanced approach as to the positive and negative aspects of them, but leans largely in support of nurses remitting to their home countries.

From the field of ethics and health policy, List $^{70}$ and Kirby and Siplon ${ }^{69}$ both argue against remittances as an economic development strategy born on the backs of nurses and other 

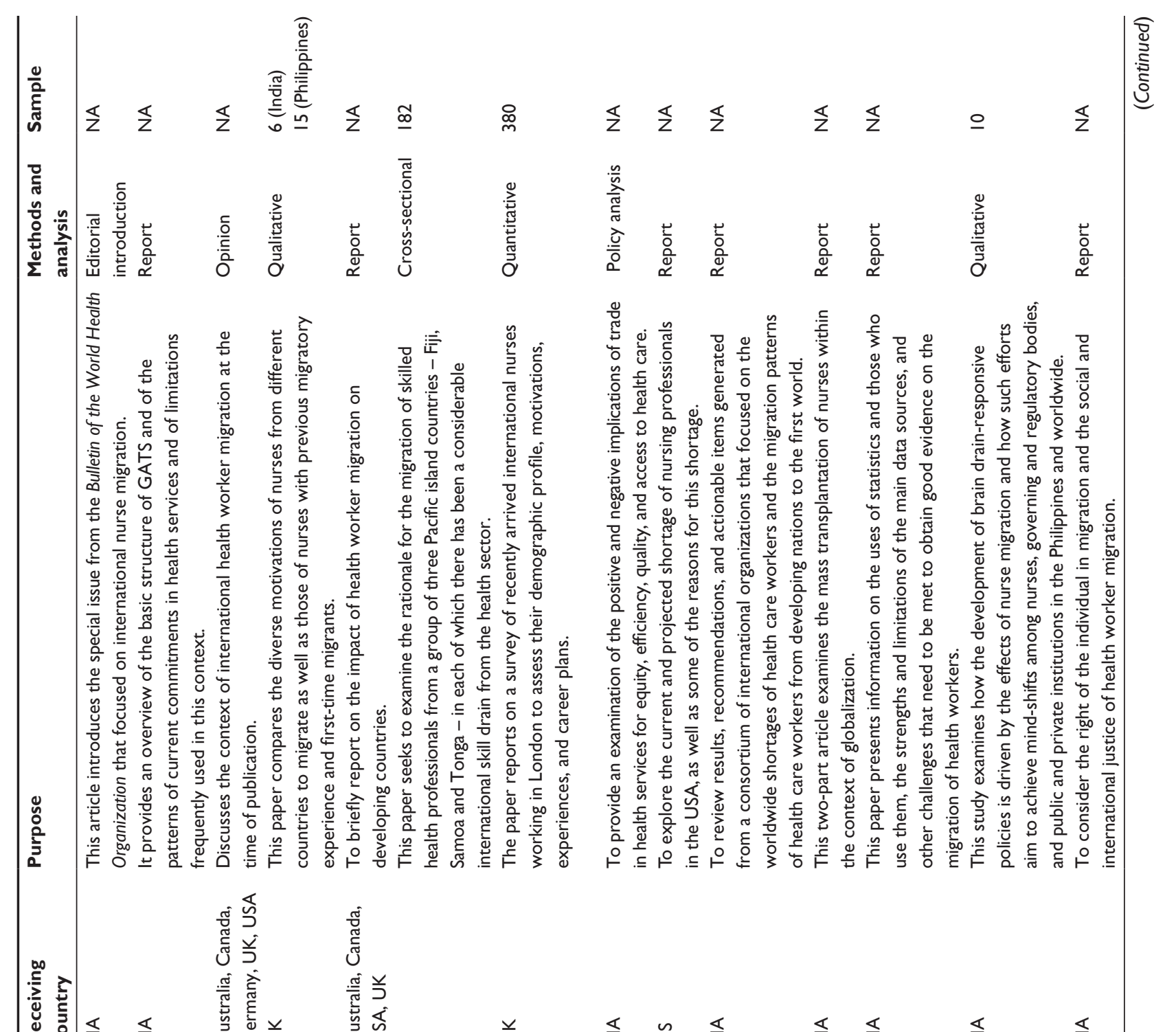


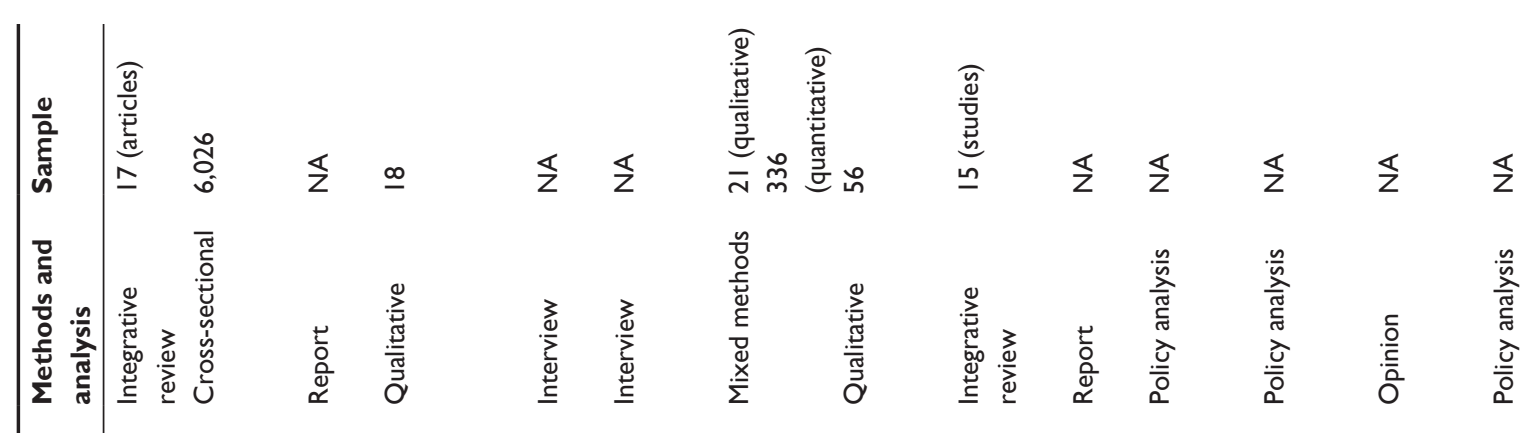

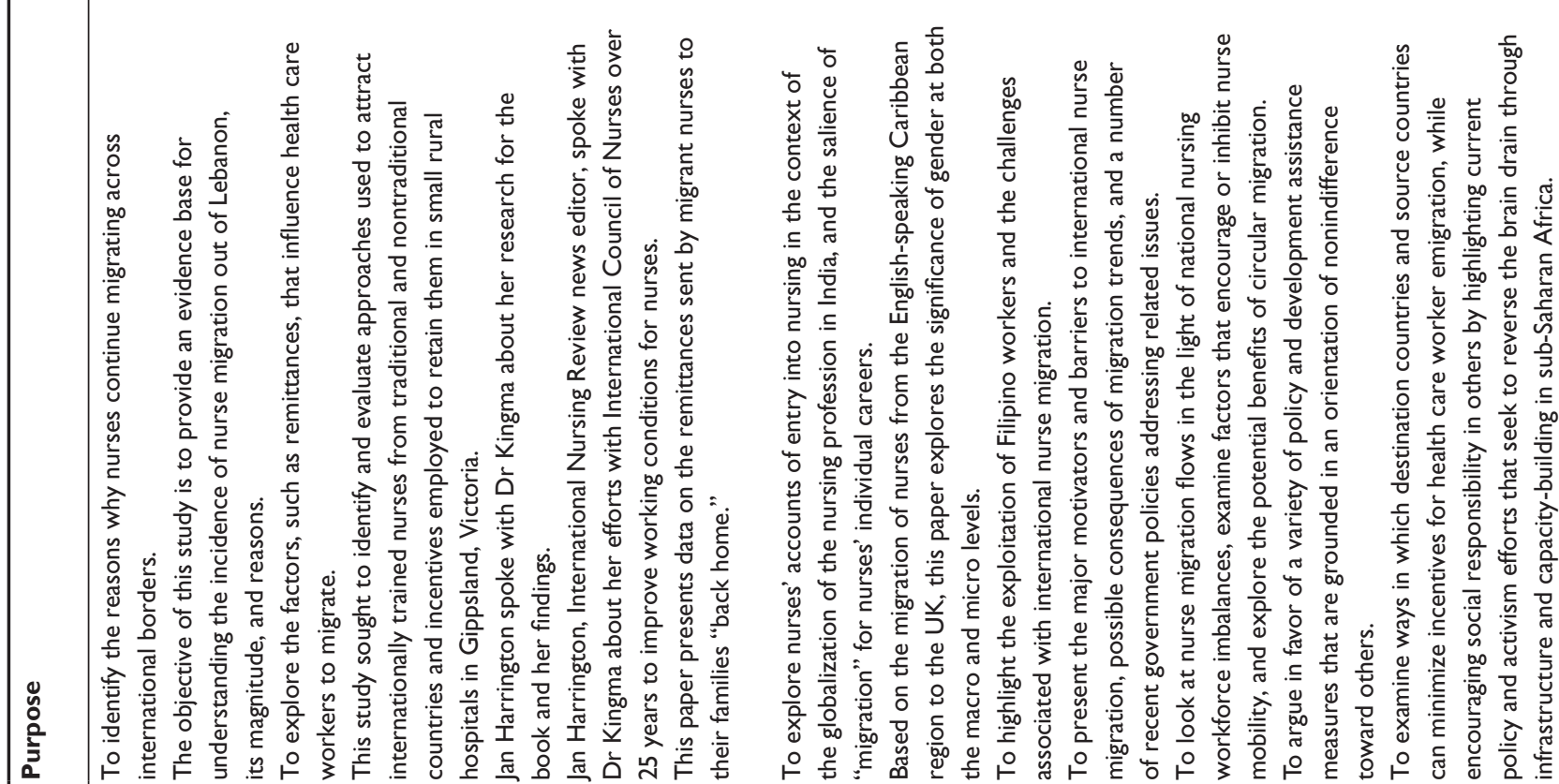

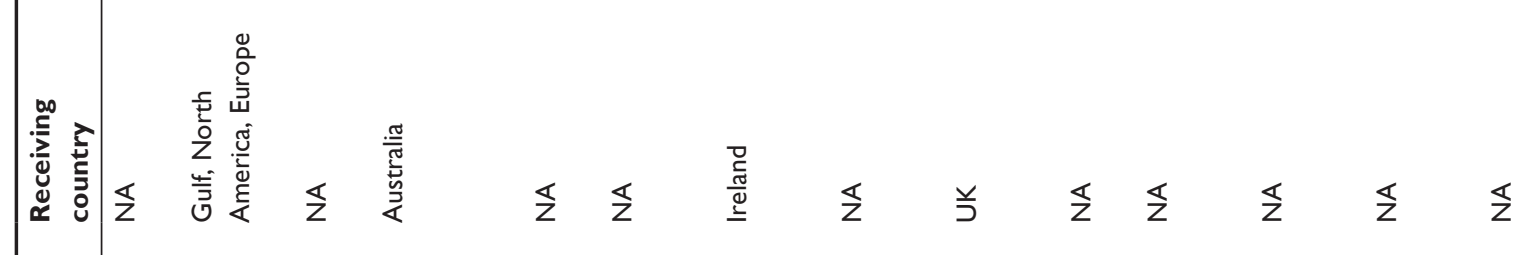

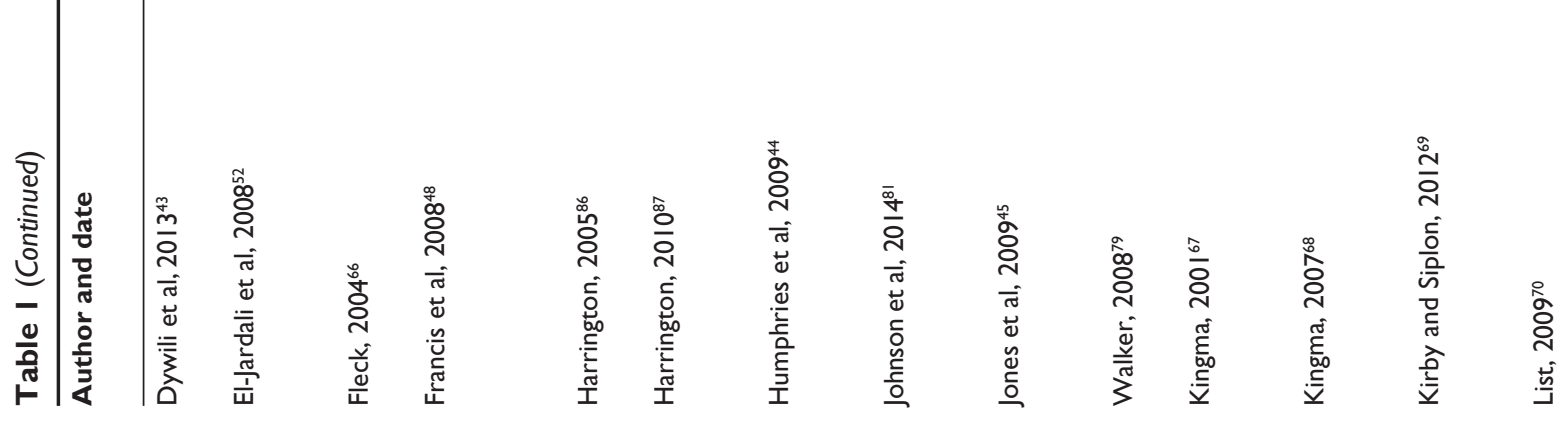

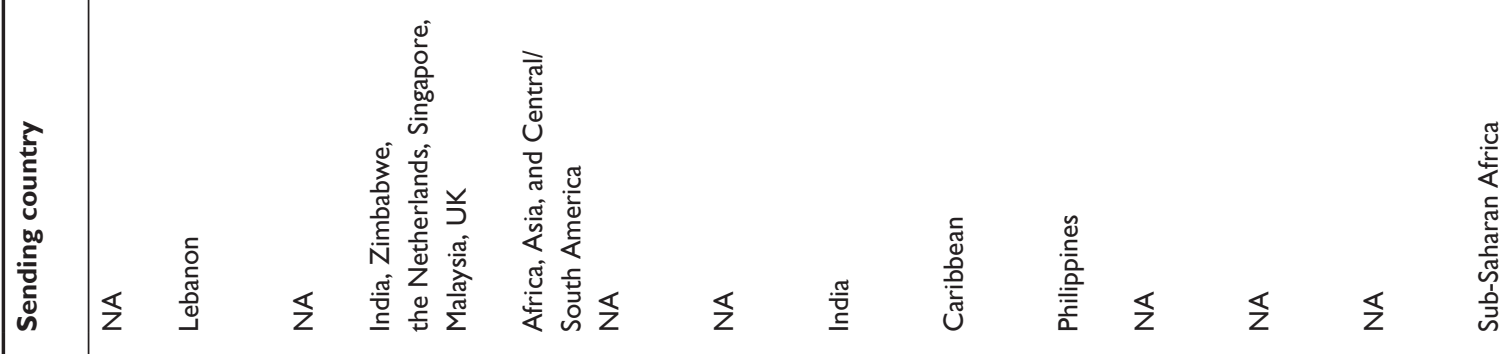




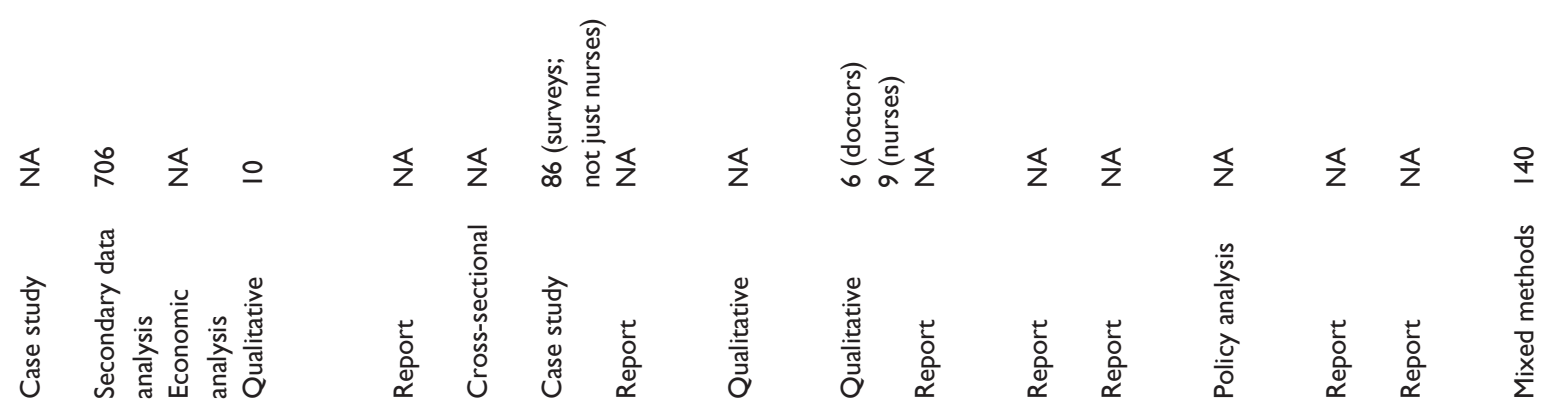

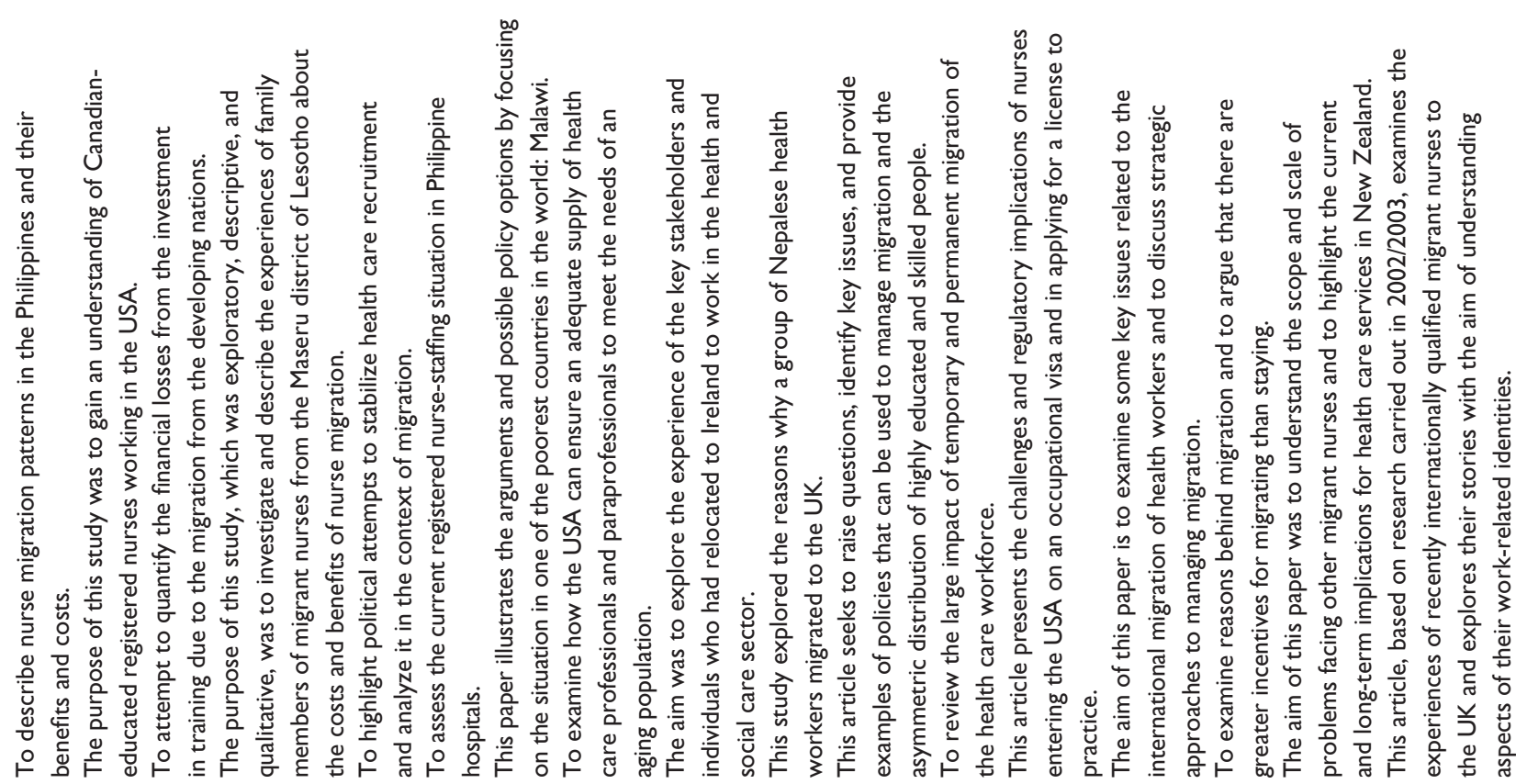

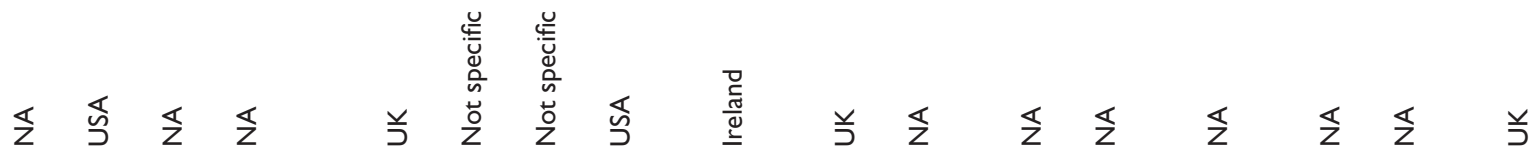

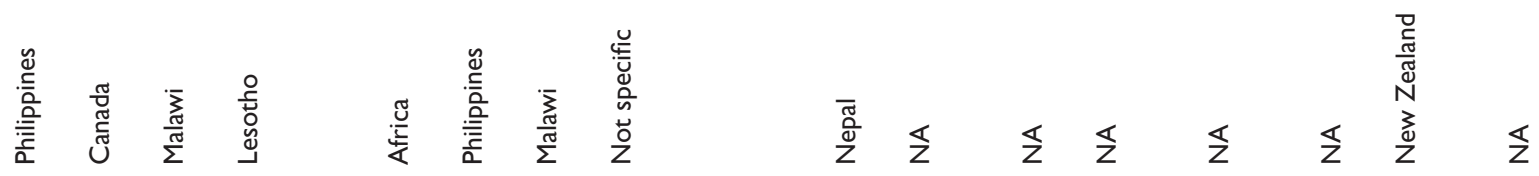

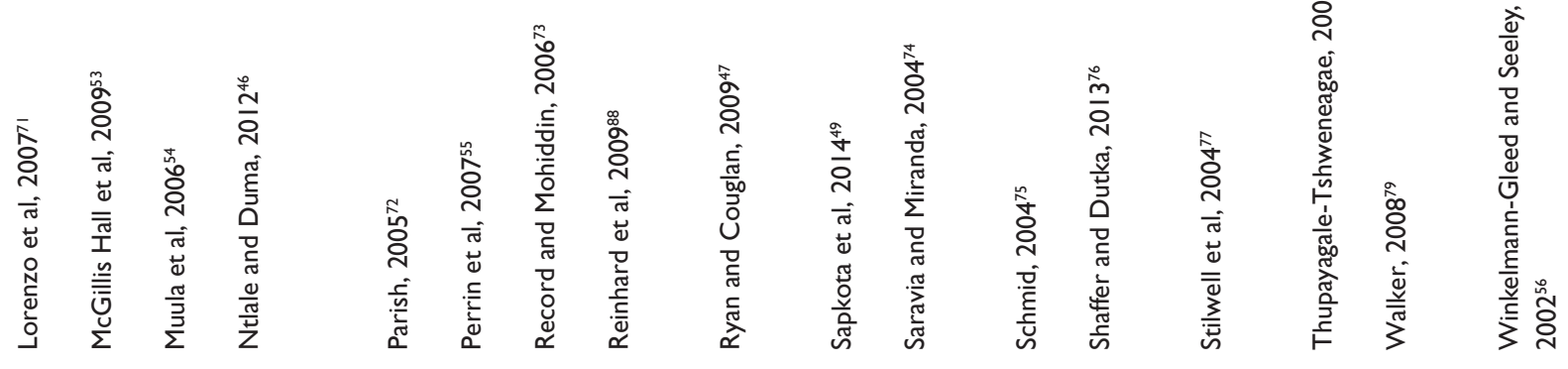


health care workers. As issues of justice, they consider the consequences of "brain drain" to health systems and patient outcomes as overriding the economic benefits. Both analyses fit into globalization and equilibrium approach theories. Their lack of consideration of the nurses' familial issues as a motivational factor in remitting is a weakness in their work.

The final set of policy analyses focused on country case studies of Malawi ${ }^{73}$ and the Philippines. ${ }^{71}$ These countries have significant histories of nurse migration that have affected their economies and health systems, but different contextual dynamics that drive the phenomenon. In the case of Malawi, an underfunded and corrupt health care system (where nurses often went months without pay) drove workers abroad until the system was near collapse. In the Philippines, state policies and infrastructure encourages international migration of health workers. A strength of both the case studies is that compared to other research approaches, they proved better at illustrating the contextual factors that drive remittances while also emphasizing their commonalities and distinctions. Their findings suggest that the dynamics of remittances need to be considered on a country by country basis.

With the general trends illustrated, we now discuss the findings from the directed content analysis. It produced two primary themes: family as motivator and gender. The female dominance of nursing as a profession contributed to these themes emerging in the analysis. This contrasts with most other research about migration and remittances since outside of nursing, migration for work is largely a male phenomenon.

\section{Family as motivator to remit}

Overall, remittances appear to be a secondary factor as a driver of migration for nurses. Not once, unless the study specifically focused on remittances, did nurses indicate that their personal desire for money as their primary motivation for migrating for work. The analysis showed that the circumstances of the nurses' families - often of low socioeconomic status or involving a family member's health crisis that caused financial strain for the family - were the primary motivators for seeking work abroad. Familial need drove the need to migrate and subsequently set the parameters for how much they would send back to their loved ones while working abroad. Husbands often also served as strong proponents of nurses migrating for work because of the potential for remittances for the family. Home needs also determined how long nurses stayed abroad for work, with some authors positing that once "home needs" were met, the nurses were more likely to return. ${ }^{51}$ 
At the same time, familial need was country dependent. Filipino nurses most often referenced family needs as reasons for sending money back home while nurses from other countries were more varied in their reasons for sending back remittances to the home country. ${ }^{41,42,55,56,71}$ Family often remained a primary reason and motivator, but often the ability to work abroad was a form of escape from family dynamics for the nurse. Remittances as a way to alleviate familial poverty, however, was not consistent across countries.

\section{Gender}

Jones et al's 2009 review of the role of gender best captured the dynamics of remittances among migrating nurses. ${ }^{45}$ Amongst its findings and those of other documents, the reliability and consistency of female migrants in remitting wages home was the primary marker of gender distinction when compared to male nurse migrants. Gender also dictated how the money was spent, with females emphasizing children's education and paying for medical care of ill relatives. ${ }^{41,56,81}$ Males tended to remit for the purpose of building houses in their home countries for their families. This theme suggests that gendered patterns of remittances among nurses needs to be explored further.

\section{Discussion}

We conclude from our analysis that the role of remittances is part of the overall migration experience of nurses, but is not the only nor the primary factor driving the phenomenon. The gender differences and familial factors also contrast findings from other disciplines that emphasize altruistic motivators behind remittances. ${ }^{82}$

The theme of "family as motivator" to remit suggests a confluence of both state and market failures to meet the basic needs of the population. If ill family members cannot receive quality care - due to limited availability, accessibility, or affordability - in the health care system, nurses may end up migrating abroad for work in response to these failures. As universal health coverage is implemented in many countries, it will be interesting to see the effects on the dynamics of INM as the need to pay for health care for family members is removed. Children's education was also another factor motivating nurses to remit, suggesting that failures in both the public and private education sectors will contribute to nurses migrating abroad for work so they can afford the best quality education for their children. Future poverty reduction initiatives, which are almost always linked to improving education, may also inadvertently shift migration dynamics. These familial and societal factors also align with neoclassical economic theory and represent diverse push factors that encourage, or pull, nurses to migrate in order to remit.

Our findings also support the work by Carling, ${ }^{4}$ who comprehensively examined the role of remittances among migrants in general in the 1980s. His conceptual model (see Figure 2) may provide a more structured way for future researchers to study remittances in nurses and other health workers. While the model is limited to micro level factors that influence remitting dynamics, the framework offers a useful way to comprehensively study the phenomenon with specific health worker populations. Future research about internationally educated nurses and remittances that seeks to study the phenomenon in-depth may benefit from its framework.

On a methodological note, it is striking how the identities of the authors shaped their views of remittances, how it was discussed or studied, and the succeeding emphasis (or lack thereof) in the publication. Qualitative research recognizes that individual researcher bias always has the potential to

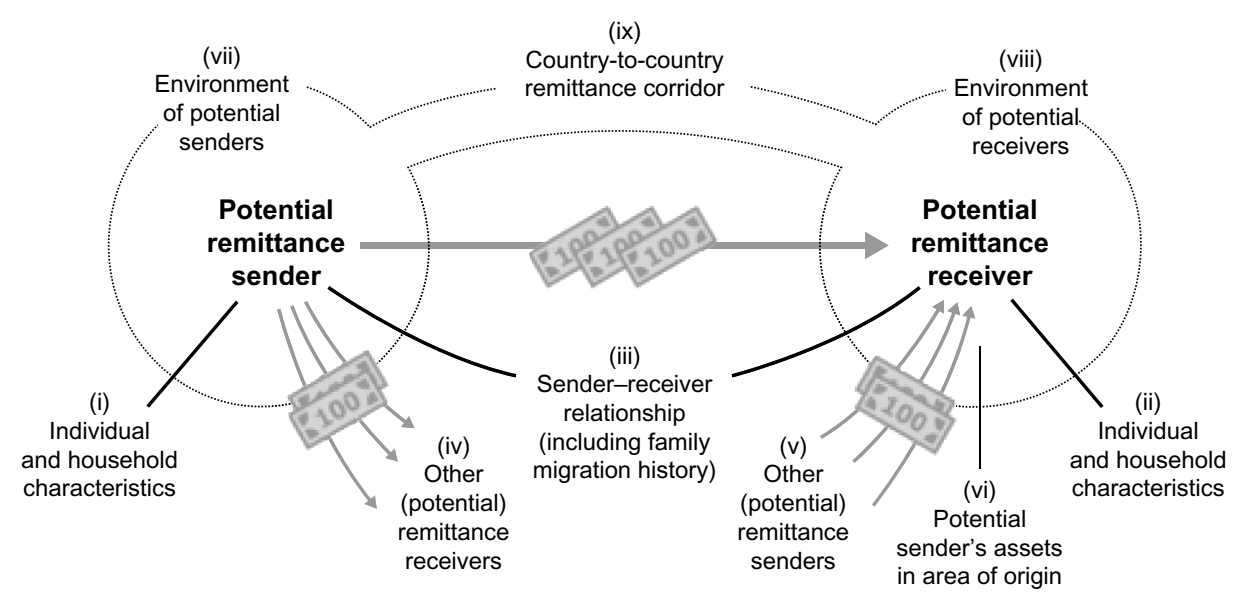

Figure 2 Carling's 2008 conceptual model for microlevel analyses of remittances. Copyright (C) 2008. Reproduced from Carling J.The determinants of migrant remittances. Oxf Rev Econ Policy. 2008;24(3):58I-598, by permission of Oxford University Press. ${ }^{4}$ 
affect the analyses, ${ }^{83}$ but other forms of research do not necessarily abide by the same principles. As we examined these data sources, it became apparent that author biases were prevalent throughout and associated with their professional discipline and/or employer. Miller and Alvarado's ${ }^{39}$ content and context mediating methods for managing documents as data sources in research proved helpful in identifying this pattern.

Two types of studies not commonly conducted in the field of nursing further added a level of contextual detail that we feel enhanced the overall analysis greatly and in particular, because they used multiple data sources. The policy analyses provided an analytic depth not found in straightforward qualitative or quantitative studies while the case studies offered the strongest contextual picture when compared to other works. These studies also reinforce the importance of and need for country-specific analyses when understanding remittances. Case study approaches can also offer the methodological flexibility needed to comprehensively analyze a country's specific remittance dynamic that other approaches cannot.

From a theoretical standpoint, our analysis suggests that in the case of nurses, household and social network theory may serve as a better analytic framework for the role of remittances in INM because of how and where nurses migrate for work. Notwithstanding that factor, equilibrium approaches may help quantify the impact of remittances and, eventually, capture both the monetary amounts behind remittances and the extent it serves as an individual motivator. Globalization, therefore, is the vehicle creating the opportunity to be able to remit home and may be the better theory for crossnational comparisons given the interconnectedness of the phenomenon.

Yet, as with any analysis, our study also had limitations. With any type of systematic review, the first source of vulnerability stems from the search terms. While we believe we were able to gather a sufficiently rich set of articles for the review, we may have missed articles that would have further added to the richness of the analysis. Our studies are also biased toward those published in English and hence, reflect the experiences of nurses migrating from countries where English is an official language. Accessing studies in other languages would have enhanced our results by adding more contexts to study. The English language emphasis in the selection criteria leaves out several regions of the world where nurse migration and remittances has unique dynamics, such as Europe. In Europe, migration and remittances occur between high-income countries, whereas our analysis focused mostly on data sources representing low- and middle-income migration to high-income countries. Another notable limitation is the lack of integration of theories and conceptual models from social science-based migration studies in our data sources. Future studies should draw more from interdisciplinary sources to frame their analyses. Finally, excluding the grey literature minimized the perspectives of international institutions such as the Organization for Economic Cooperation and Development, the World Bank, and the Migration Policy Institute - all well respected international institutions or think tanks that contribute significant research to the remittances literature. A future review could focus on that literature exclusively due to sheer volume.

\section{Conclusion}

Remittances will always remain part of the INM experience. The role they play, as this analysis suggests, is part of a larger picture that is closely related to domestic labor market dynamics and the nurse's family. Both merit further examination in future research studies, with gender-sensitive analyses strongly recommended as part of any method used to study the phenomenon. Future policy work should include more comparative analyses of the role of the state and domestic health care labor market policies and how those factor into the remittances picture or migration pattern.

Above all else, with all INM dynamics it is important to remember that if nurses cannot get jobs that pay middleclass salaries, if there is a hostile work environment, if there is little room for professional advancement, or if patient assignment loads are so high that the workforce burns out quickly, nurses will migrate for one or all of those reasons. Furthermore, when large numbers of nurses emigrate, it does little to improve the local work environment, thus contributing to a cycle of poor opportunities and large-scale emigration. Working abroad to remit money home may be a commentary made by the feet of nurses about the current state of the health care system and its management.

\section{Acknowledgment}

AS would like to acknowledge the financial support received for this work as part of her Fellowship with the Migration Policy Institute in Washington, DC.

\section{Author contributions}

AS conceived the study design, search strategy, and wrote the majority of the paper. AA conducted the literature search, organized the coding schematic, and contributed to the writing and formatting of the paper. 


\section{Disclosure}

AS is currently a nonresident research fellow of the Migration Policy Institute, a Washington DC-based, nonpartisan think tank that examines the global migration of individuals. She receives some salary support for her work with the institute. AS is also a consultant for the World Bank on health labor markets analyses. AS reports no other conflicts of interest in this work. AA reports no conflicts of interest in this work.

\section{References}

1. World Health Organization. The WHO Global CODE of Practice on the International Recruitment of Health Personnel. Geneva: World Health Organization; 2010. Available from: http:/www.who.int/hrh/migration/ code/code_en.pdf. Accessed July 16, 2014.

2. World Health Organization. Working Together for Health: The World Health Report 2006. Geneva: World Health Organization; 2006. Available from: http://www.who.int/whr/2006/whr06_en.pdf?ua=1. Accessed January 31, 2014.

3. Nair M, Webster P. Health professionals' migration in emerging market economies: patterns, causes and possible solutions. J Public Health (Oxf). 2013;35(1):157-163.

4. Carling J. The determinants of migrant remittances. Oxf Rev Econ Policy. 2008;24(3):581-598.

5. Smith RD, Chanda R, Tangcharoensathien V. Trade in health-related services. Lancet. 2009;373(9663):593-601.

6. Buchan J, Parkin T, Sochalski J. International Nurse Mobility: Trends and Policy Implications. Geneva: World Health Organization; 2003. Available from: http://whqlibdoc.who.int/hq/2003/WHO_EIP_ OSD_2003.3.pdf. Accessed January 31, 2014.

7. International Centre on Nurse Migration. Nursing Self Sufficiency/ Sustainability in the Global Context. Geneva: International Centre on Nurse Migration and the International Centre for Human Resources in Nursing; 2007. Available from: http://www.intlnursemigration.org/ assets/pdfs/SelfSufficiency_US.pdf. Accessed February 4, 2014.

8. Kingma M. Nurse migration and the global health care economy. Policy Polit Nurs Pract. 2008;9(4):328-333.

9. Sana M. Growth in migrant remittances from the United States to Mexico, 1994-2004. Soc Forces. 2008;83(3):995-1025.

10. Zárate Hoyos GA. International labor migration as a strategy of economic stabilization at the household level in Mexico and Central America. Papeles Poblac. 2008;4(56):19-36.

11. Aboderin I. Contexts, motives and experiences of Nigerian overseas nurses: understanding links to globalization. J Clin Nurs. 2007;16(12): 2237-2245.

12. Anderson BA, Isaacs AA. Simply not there: the impact of international migration of nurses and midwives - perspectives from Guyana. J Midwifery Womens Health. 2007;52(4):392-397.

13. Brush BL. Global nurse migration today. J Nurs Scholarsh. 2008;40(1): 20-25.

14. Pittman P, Aiken LH, Buchan J. International migration of nurses: introduction. Health Serv Res. 2007;42(3 Pt 2):1275-1280.

15. Stilwell B, Diallo K, Zurn P, Dal Poz MR, Adams O, Buchan J. Developing evidence-based ethical policies on the migration of health workers: conceptual and practical challenges. Hum Resour Health. 2003;1(1):8.

16. Denton S. Nation-to-nation challenges to addressing the effects of emerging global nurse migration on health care delivery. Policy Polit Nurs Pract. 2006;7(Suppl 3):76S-80S.

17. Hawthorne L. The globalisation of the nursing workforce: barriers confronting overseas qualified nurses in Australia. Nurs Inq. 2001;8(4): 213-229.

18. Jeans ME. In-country challenges to addressing the effects of emerging global nurse migration on health care delivery. Policy Polit Nurs Pract 2006;7(Suppl 3):58S-61S.
19. Kingma M. Nurses on the Move: Migraiton and the Global Health Care Economy. Ithaca, NY: Cornell University Press; 2006.

20. De Leon Saintz ML, Malvarez S. Migration of nurses: a Latin American perspective. Online J Issues Nurs. 2008;13(2):7. Available from: http:// www.nursingworld.org/MainMenuCategories/ANAMarketplace/ ANAPeriodicals/OJIN/TableofContents/vol132008/No2May08/ LatinAmericanPerspective.aspx.

21. Nichols J, Campbell J. The experiences of internationally recruited nurses in the UK (1995-2007): an integrative review. J Clin Nurs. 2010;19(19-20):2814-2823.

22. Rosenkoetter MM, Nardi DA. American Academy of Nursing Expert Panel on Global Nursing and Health: white paper on global nursing and health. J Transcult Nurs. 2007;18(4):305-315.

23. Salmon ME, Yan J, Hewitt H, Guisinger V. Managed migration: the Caribbean approach to addressing nursing services capacity. Health Serv Res. 2007;42(3 Pt 2):1354-1372.

24. Smith P, Mackintosh M. Profession, market and class: nurse migration and the remaking of division and disadvantage. J Clin Nurs. 2007;16(12):2213-2220.

25. Bach S. Going global? The regulation of nurse migration in the UK Br J Ind Relations. 2007;45(2):383-403.

26. Cimoli M, Porcile G. Global growth and international cooperation: a structuralist perspective. Cambridge J Econ. 2011;35(2):383-400.

27. Mattoo A, Mishra D. Foreign professionals in the United States: regulatory impediments to trade. J Int Econ Law. 2009;12(2):435-456.

28. Adlung R, Morrison P. Less than the GATS: "negative preferences" in regional services agreements. J Int Econ Law. 2010;13(4):1103-1143.

29. Babones SJ, Vonada DC. Trade globalization and national income inequality - are they related? J Sociol. 2009;45(1):5-30.

30. Shadlen KC. Latin American trade and development in the new international economy. Lat Am Res Rev. 2006;41(3):210-221.

31. Deeming C. Policy targets and ethical tensions: UK nurse recruitment. Soc Policy Adm. 2004;38(7):775-792.

32. Garip F. Social capital and migration: how do similar resources lead to divergent outcomes? Demography. 2008;45(3):591-617.

33. Robinson S, Murrells T, Griffiths P. Investigating the dynamics of nurse migration in early career: a longitudinal questionnaire survey of variation in regional retention of diploma qualifiers in England. Int J Nurs Stud. 2008;45(7):1064-1080.

34. Drevdahl DJ, Dorcy KS. Exclusive inclusion: the violation of human rights and US immigration policy. ANS Adv Nurs Sci. 2007;30(4): $290-302$.

35. Humphries N, Brugha R, McGee H. Overseas nurse recruitment: Ireland as an illustration of the dynamic nature of nurse migration. Health Policy. 2008;87(2):264-272.

36. Squires A, Beltrán-sánchez H. Strengthening Health Systems in North and Central America: What Role for Migration? Washington, DC: Wilson Center; 2013. Available from: http://www.wilsoncenter.org/ sites/default/files/strengthening_health_systems.pdf. Accessed January $31,2014$.

37. Whittemore R, Knafl K. The integrative review: updated methodology. J Adv Nurs. 2005;52(5):546-553.

38. Hsieh HF, Shannon SE. Three approaches to qualitative content analysis. Qual Health Res. 2005;15(9):1277-1288.

39. Miller FA, Alvarado K. Incorporating documents into qualitative nursing research. J Nurs Scholarsh. 2005;37(4):348-353.

40. Buchan J, O'May F, Dussault G. Nursing workforce policy and the economic crisis: a global overview. J Nurs Scholarsh. 2013;45(3): 298-307.

41. Alonso-Garbayo A, Maben J. Internationally recruited nurses from India and the Philippines in the United Kingdom: the decision to emigrate. Hum Resour Health. 2009; 7:37.

42. Dimaya RM, McEwen MK, Curry LA, Bradley EH. Managing health worker migration: a qualitative study of the Philippine response to nurse brain drain. Hum Resour Health. 2012;10(1):47.

43. Dywili S, Bonner A, O'Brien L. Why do nurses migrate? - a review of recent literature. J Nurs Manag. 2013;21(3):511-520. 
44. Humphries N, Brugha R, McGee H. Sending money home: a mixedmethods study of remittances by migrant nurses in Ireland. Hum Resour Health. 2009;7:66.

45. Jones AD, Bifulco A, Gabe J. Caribbean nurses migrating to the UK: a gender-focused literature review. Int Nurs Rev. 2009;56(3):285-290.

46. Ntlale ME, Duma SE. The costs and benefits of nurse migration on families: A Lesotho experience. Curationis. 2012;34(1):E1-E8.

47. Ryan D, Couglan D. Inward labour mobility in the Irish health- and social-care sector. Br J Nurs. 2009;18(3):192-197.

48. Francis K, Chapman Y, Doolan G, Sellick K, Barnett T. Using overseas registered nurses to fill employment gaps in rural health services: quick fix or sustainable strategy? Aust J Rural Health. 2008;16(3): 164-169.

49. Sapkota TN, van Teijlingen E, Simkhada PP. Nepalese health workers' migration to the United Kingdom: a qualitative study. Heal Sci J. 2014;8(1):57-74.

50. Brown RPC, Connell J. The migration of doctors and nurses from South Pacific island nations. Soc Sci Med. 2004;58(11):2193-2210.

51. Buchan J, Jobanputra R, Gough P, Hutt R. Internationally recruited nurses in London: a survey of career paths and plans. Hum Resour Health. 2006;4:14.

52. El-Jardali F, Dumit N, Jamal D, Mouro G. Migration of Lebanese nurses: a questionnaire survey and secondary data analysis. Int J Nurs Stud. 2008;45(10):1490-1500.

53. McGillis Hall L, Pink GH, Jones CB, Leatt P, Gates M, Peterson J. Is the grass any greener? Canada to United States of America nurse migration. Int Nurs Rev. 2009;56(2):198-205.

54. Muula AS, Panulo B, Maseko FC. The financial losses from the migration of nurses from Malawi. BMC Nurs. 2006;5:9.

55. Perrin ME, Hagopian A, Sales A, Huang B. Nurse migration and its implications for Philippine hospitals. Int Nurs Rev. 2007;54(3): 219-226.

56. Winkelmann-Gleed A, Seeley J. Strangers in a British world? Integration of international nurses. Br J Nurs. 2005;14(18):954-961.

57. McPake B, Maeda A, Araújo EC, Lemiere C, El Maghraby A, Cometto G. Why do health labour market forces matter? Bull World Health Organ. 2013;91(11):841-846.

58. Adams O, Stilwell B. Health professionals and migration. Bull World Health Organ. 2004;82(8):560.

59. Adlung R, Carzaniga A. Health services under the General Agreement on Trade in Services. Bull World Health Organ. 2001;79(4):352-364.

60. Ahmad OB. Brain drain: the flight of human capital. Bull World Health Organ. 2004;82(10):797-798.

61. Migration threatens health systems in developing countries. Aust Nurs J. 2006;13(6): 10 .

62. Chanda R. Trade in health services. Bull World Health Organ. 2002;80(2):158-163.

63. Christmas K, Hart KA. Workforce shortages are a global issue. Nurs Econ. 2007;25(3):175-177.

64. Cutcliffe JR, Yarbrough S. Globalization, commodification and mass transplant of nurses: Part 1. Br J Nurs. 2007;16(15):926-930.

65. Diallo K. Data on the migration of health-care workers: sources, uses, and challenges. Bull World Health Organ. 2004;82(8):601-607.

66. Fleck F. Should I stay or should I go? Bull World Health Organ. 2004; 82(8):634
67. Kingma M. Nursing migration: global treasure hunt or disaster-in-themaking? Nurs Inq. 2001;8(4):205-212.

68. Kingma M. Nurses on the move: a global overview. Health Serv Res. 2007;42(3 Pt 2):1281-1298.

69. Kirby KE, Siplon P. Push, pull, and reverse: self-interest, responsibility, and the global health care worker shortage. Health Care Anal. 2012; 20(2):152-176.

70. List JM. Justice and the reversal of the healthcare worker 'brain-drain'. Am J Bioeth. 2009;9(3):10-12.

71. Lorenzo FM, Galvez-Tan J, Icamina K, Javier L. Nurse migration from a source country perspective: Philippine country case study. Health Serv Res. 2007;42(3 Pt 2):1406-1418.

72. Parish C. Nurses and doctors unite in call for an end to African skills drain. Nurs Stand. 2005;19(41):5.

73. Record R, Mohiddin A. An economic perspective on Malawi's medical "brain drain". Global Health. 2006;2:12.

74. Saravia NG, Miranda JF. Plumbing the brain drain. Bull World Health Organ. 2004;82(8):608-615.

75. Schmid K. Strategies to manage migration of health professionals to protect national health systems will be successful only if all stake-holders are involved in the process. Bull World Health Organ. 2004;82(8): 621-622.

76. Shaffer FA, Dutka JT. Global mobility for internationally educated nurses: challenges and regulatory implications. JNurs Regul. 2013;4(3): $11-16$.

77. Stilwell B, Diallo K, Zurn P, Vujicic M, Adams O, Dal Poz M. Migration of health-care workers from developing countries: strategic approaches to its management. Bull World Health Organ. 2004;82(8):595-600.

78. Thupayagale-Tshweneagae G. Migration of nurses: is there any other option? Int Nurs Rev. 2007;54(1):107-109.

79. Walker L. A mixed picture: the experiences of overseas-trained nurses in New Zealand. Nurs N Z. 2008;14(11):18-19.

80. Zivotofsky AZ, Zivotofsky N. Are healthcare workers chained to their country of origin? Am J Bioeth. 2009;9(3):16-18.

81. Johnson SE, Green J, Maben J. A suitable job?: A qualitative study of becoming a nurse in the context of a globalizing profession in India. Int J Nurs Stud. 2014;51(5):734-743.

82. Lucas RE, Stark O. Motivations to remit: evidence from Botswana. J Polit Econ. 1985;93(5):901-918.

83. Sandelowski M, Barroso J. Classifying the findings in qualitative studies. Qual Health Res. 2003;13(7):905-923.

84. Chandra A, Willis WK. Importing nurses: combating the nursing shortage in America. Hosp Top. 2005;83(2):33-37.

85. Dwyer J. What's wrong with the global migration of Health Care Professionals? Individual rights and international justice. Hastings Cent Rep. 2007;37(5):36-43.

86. Global ICN Report says supply of nurses affects health care outcomes. Int Nurs Rev. 2005;52(1):4-5.

87. Three countries launch projects to promote healthy workplaces. Int Nurs Rev. 2010;57:155-157.

88. Reinhard S, Redfoot D, Cleary B. Health and Long-Term Care: Are Immigrant Workers Indispensable? Am Soc Aging. 2009;32:24-30.

89. Xu Y, Zhang J. One size doesn't fit all: Ethics of international nurse recruitment from the conceptual framework of stakeholder interests. Nurs Ethics. 2005;12:571-581.

Nursing: Research and Reviews

\section{Publish your work in this journal}

Nursing: Research and Reviews is an international, peer-reviewed, open access journal publishing original research, reports, reviews and commentaries on all aspects of nursing and patient care. These include patient education and counselling, ethics, management and organizational issues, diagnostics and prescribing, economics and

resource management, health outcomes, and improving patient safety in all settings. The manuscript management system is completely online and includes a very quick and fair peer-review system. Visit http://www.dovepress.com/testimonials.php to read real quotes from published authors. 